\title{
DISPOSITIVOS ABERTOS E INOVAÇÃO NA EDUCAÇÃO SUPERIOR: COGNIÇÃO E FLEXIBILIDADE.
}

\author{
Susane Garrido* \\ Miryan Celaro**
}

Resumo: Novas formas de pensar, de comunicar e de aprender desafiam as universidades na implementação de dispositivos flexíveis e alternativos, compatíveis com a multiplicidade $e$ simultaneidade de operações, funções e situações que envolvem o adulto-universitário- trabalhador. Esse brief paper pretende apontar para um novo domínio de competências cognitivas e comunicativas necessárias para este usuário-aprendiz, a partir de uma experiência prática de curso a distância em ensino superior com suporte em tecnologia digital.

Palavras chaves: Cognição, Tecnologia, Comunicação.

\section{OPEN DEVICES AND INNOVATION IN EDUCATION AT THE UNIVERSITY: COGNITION AND FLEXIBILITY}

\begin{abstract}
New ways of thinking, communicating and learning challenge universities when it comes to implementing flexible and alternative devices, compatible with the multiplicity and simultaneity of operations, functions and situations that are related to the adult-student-worker. This brief paper intends to point to a new domain of cognitive and communicative competences necessary for this user-learner, with a practical experience of a distance course in graduation with digital technology support.
\end{abstract}

Keywords: Cognition, Technology, Communication

\section{INTRODUÇÃO}

Um novo sentido está sendo dado para a cognição humana frente à tecnologia, segundo Andler (1998; p55) a cognição deve ser percebido como uma intrínseca relação entre a estrutura formal e biológica do indivíduo e suas expressões psicológicas, antropológicas, filosóficas e lingüísticas . Este entendimento sinaliza para o surgimento de um novo sujeito, diretamente afetado pela virtualidade dos ambientes que se nos apresentam.

As iniciativas geradoras de flexibilidade no ensino superior, entre as quais as de educação a distância, modificam, neste sujeito, a percepção da relação com o tempo e o ritmo.

Cabe aqui, para melhor caracterizar este novo sujeito, a denominação de usuárioaprendiz, apresentado por Jacquinot (apud Celaro, 2003), que enfatiza diferentes

\footnotetext{
* Susane Martins Lopes Garrido é Mestre em Educação (PUCRS) e Doutoranda em Informática na Educação (UFRGS). É professora na UNISINOS e Assistente para as áreas de Educação e Tecnologias na Educação Email: Susane@ bage.unisinos.br.

** Miryan Celaro é Doutoranda em Engenharia de Produção/Midias e Conhecimento na UFSC. É Professora na UNISINOS e Assistente para as áreas de Comunicação e Tecnologias na Educação Email: miryan@mercurio.unisinos.br
} 
"estados" no mesmo sujeito. Estes "estados" incluem o usuário-consumidor de produtos educacionais, o usuário-cidadão (receptor da mensagem), ou também chamado usuário-negociador (o estado final), o usuário enquanto beneficiário do sistema/dispositivo/rede de aprendizagem $e$ o usuário de tecnologias. Para fins deste estudo consideramos estes dois últimos "estados".

O grau de imprevisibilidade que esta flexibilidade apresenta constitui um dos aspectos relevantes nos estudos cognitivos da atualidade enquanto desafio para iniciativas inovadoras no ensino superior. Na prática, os dispositivos flexíveis com suporte em tecnologias de informação e comunicação para uso em educação a distância, potencializam, no usuário-aprendiz o desenvolvimento de novas competências cognitivas para ampliação e transformação das noções de concretude, de previsibilidade e de inflexibilidade dantes construídas.

\section{COGNIÇÃO E TECNOLOGIA}

Atualmente um Curso de Especialização está em desenvolvimento na UNISINOS (Universidade do Vale do Rio dos Sinos-RS) desde abril de 2003 com previsão de término em dezembro deste ano. Está sendo oferecido na modalidade a distância e utiliza uma interface virtual denominada AVA.

O AVA (Ambiente Virtual de Aprendizagem), elaborado por uma equipe da Universidade, decorre de uma concepção interacionista de construção do conhecimento, na qual o aluno é o centro do processo de aprendizagem e de construção do próprio ambiente.

Até o mês de junho o Curso contava com 38 alunos matriculados, dentre estes, a maioria professores de escolas públicas e privadas do Rio Grande do Sul e de Santa Catarina.

A heterogeneidade, em termos de culturas, idade, escolaridade, experiências prévias deste grupo de alunos marca a necessidade de considerar diferentes ritmos e tempos de aprendizagem.

Dessa forma foram construídos dois quadros de categorias a fim de mapear o panorama de diversidade de ritmos e de tempos que se apresentam no curso com a perspectiva de personalizar a relação com cada usuário-aprendiz da comunidade.

Esse artigo pretende demonstrar (em síntese), as diversidades das relações de tempo e ritmo em uma experiência prática de curso a distância em ensino superior e a necessidade desta flexibilização.

\section{Quadro I: Mapeamento de Ritmos}

Mapeamento de Ritmos:

- ritmo lento de respostas e sem dificuldades (aparentes) com a tecnologia; $34 \%$

- ritmo lento de respostas e com dificuldades (aparentes) com a tecnologia; $21 \%$

- ritmo rápido de respostas e sem dificuldades (aparentes) com a tecnologia; $13 \%$

- ritmo rápido de respostas e sem dificuldades (aparentes) com a tecnologia... ( são do OK: isto já basta!)

- os estudantes perdidos; $10 \%$

- os não adaptados à modalidade de EAD mas que a suportam; 
- ritmo rápido de respostas e sem dificuldades (aparentes) com a tecnologia com expectativa com relação a um ritmo mais acelerado de trabalho, ou seja, o que mais??

- os que precisam de uma aproximação constante (via telefone ou visitas) e que mesmo assim, não reagem produtivamente;

Percebe-se com esse breve panorama, que há uma grande maioria que reage de uma forma mais lenta aos desafios propostos, possivelmente porque fatores como envolvimento com o trabalho (uma vez que esses alunos são em sua maioria, trabalhadores), dificuldades com o uso de algumas metodologias, necessidade de uma reorganização da vida pessoal e familiar, e ainda dificuldades com equipamentos podem estar interferindo nesses resultados. Essa situação necessita ser mais profundamente investigada.

Entretanto, a minoria que reage rapidamente reivindica ativamente um outro tipo de tratamento, ou seja, um ritmo mais acelerado do curso.

Este ponto de tensão evidencia a necessidade de aprofundamento da reflexão com relação a uma visão mais ampla sobre a flexibilização. Aponta, portanto para uma revisão mais abrangente envolvendo programas de aprendizagem, metodologias, recursos, docentes e outros. É significativamente maior o envolvimento do professor com a multiplicidade de situações que se desdobram a partir da flexibilização do ritmo e da personalização da aprendizagem. A tentativa de criar subgrupos é uma alternativa a ser estudada.

\section{Quadro II: O Quadro a seguir é uma síntese disponível no AVA que evidencia a interação, em termos de tempo, dos alunos do Curso:}

\section{Totais gerais do ambiente}

Número geral de acessos ao ambiente: 22398 acesso(s)

das 00:00:00 às 01:00:00

I 270 acesso(s)

| $1.2 \%$ 
das 01:00:00 às 02:00:00

das 02:00:00 às 03:00:00
I 137 acesso(s)

I 50 acesso(s)
$10.61 \%$

I $0.22 \%$ das 03:00:00 às 04:00:00

das 04:00:00 às 05:00:00

das 05:00:00 às 06:00:00

das 06:00:00 às 07:00:00

das 07:00:00 às 08:00:00

das 08:00:00 às 09:00:00

das 09:00:00 às 10:00:00

das 10:00:00 às 11:00:00

das 11:00:00 às 12:00:00

das 12:00:00 às 13:00:00

das 13:00:00 às 14:00:00

das 14:00:00 às 15:00:00

das 15:00:00 às 16:00:00

das 16:00:00 às 17:00:00

das 17:00:00 às 18:00:00

das 18:00:00 às 19:00:00

das 19:00:00 às 20:00:00

das 20:00:00 às 21:00:00

das 21:00:00 às 22:00:00

das 22:00:00 às 23:00:00

das 23:00:00 às 24:00:00
I 19 acesso(s)

$10.08 \%$

I 15 acesso(s)

19 acesso(s)

I 19 acesso(s)

I 155 acesso(s)

$10.06 \%$

| $0.04 \%$

$10.08 \%$

$10.69 \%$

I 1182 acesso(s)

$15.27 \%$

| 1455 acesso(s)

$16.49 \%$

| 1538 acesso(s)

$16.86 \%$

| 1261 acesso(s)

$15.62 \%$

I 677 acesso(s)

$13.02 \%$

I 1135 acesso(s)

$15.06 \%$

| 1746 acesso(s)

| 1462 acesso(s)

| 1391 acesso(s)

| 1202 acesso(s)

$17.79 \%$

| $6.52 \%$

$6.21 \%$

| $5.36 \%$

I 1162 acesso(s)

$15.18 \%$

I 2498 acesso(s)

| $11.15 \%$

| 2293 acesso(s)

| 1711 acesso(s)

I $10.23 \%$

$17.63 \%$

$12.71 \%$

| $1.8 \%$

Desse quadro pode-se evidenciar uma grande diversidade de uso do tempo para interações com o ambiente virtual no qual está o curso. Não há, apesar de um pico de entrada entre 19:00h e 21:00h (aproximadamente 29\%) um padrão para essas interações. Alguns freqüentam o ambiente entre $1 \mathrm{~h}$ e $7 \mathrm{~h}$ da manhã, ou seja $3 \%$ ou 674 acessos. Outros se distribuem ao longo do dia com uma pequena redução dos acessos entre $12 \mathrm{~h}$ e $13 \mathrm{~h}$ e uma preferência pelo horário das $14 \mathrm{~h}$. Os dias da semana também não são todos iguais. Há uma variação nas entradas em feriados, sábados e domingos. A relação horário e dia da semana permite ainda observar usuários totalmente diferentes em sua trajetória de navegação, de organização dos tempos de estudo.

A experiência vem demonstrando ainda que o acesso ao ambiente põe em evidência essa relação híbrida concreto-virtual a qual é absorvida entre momentos de tensão e de entusiasmo. É ainda misterioso para o grupo em estudo "este outro lugar, que desconhece uma existência física análoga à que suporta nossos referenciais concretos do dia-a-dia". A busca insistente, pelos aprendizes, do retorno "ao calor humano da sala de aula tradicional" alimentam as indagações sobre os "contextos propostos pela tecnologia e o desconcerto do sujeito que produz sentido sem o apoio da materialidade presentificável do seu objeto de interação". Estes dois mundos se entrelaçam, conforme depoimento do usuário1: 
“(...)19 professores inscritos no curso 6 são da educação física e 13 da 5a-8a e ensino médio.

Para facilitar as coisas nos dividimos em 2 grupos, o da educação física que fica sob a orientação da profa Idala e os demais comigo. Para auxiliar os colegas tenho feito xerox dos e-mails e materiais mais importantes e distribuído uma copia para cada um dos 19 professores. Na quarta passada tivemos o primeiro encontro do pessoal do ensino médio, conseguimos o lab de informática e nos reunimos as 18:30 ate as 19;45. Foi bastante proveitoso, conseguimos ajudar aqueles que tinham maior dificuldade. Até conseguimos criar um chat e todos se divertiram muito com ele. Esta semana devo preparar e reproduzir materiais que auxiliem nas atividades 2.1 e 2.2. Que achas de nossa estratégia??"

Segundo alguns autores, entre os quais Maturana (2001), Damásio (2001), Fialho(2001) é preciso um novo domínio de competências cognitivas para a tecnologia digital e acrescentam a essa reflexão, questões que apontam para a relação entre cognição e emoção. A perda da terra e do controle diante de uma situação inusitada e desconhecida, amplifica a ausência de alguém capaz de ouvir e de responder (ainda que por telefone), conforme depoimento do usuário2:

(...)"Após ter dedicado um tempo para explorar o ambiente vi que não é tão difícil como parecia. Algumas "coisas" foram impressas para que eu pudesse ler "fora" do computador. Fazer a leitura numa tela para mim ainda é uma novidade e uma dificuldade a ser superada. (...) Quando fui "descadastrada" da comunidade deu um pânico. E agora o que eu iria fazer. Tudo se resolveu com uma conversa "(...)

Outros alunos não resistiram a tentação de comparecer à universidade para encontrar os professores "em carne e osso".

Para Hurssel (apud Axt, 2001) "a perda da terra" quer dizer a perda do aquiagora. E se o espaço-tempo forem atingidos e atacados pela digitalização também o corpo o será (Lyotard apud Axt, 2001). Para Quéau (apud Axt) a generalização de mundos virtuais não poderá deixar de virtualizar o mundo e tornar-nos simultaneamente nós mesmos mais ou menos virtuais.

Tais vivências-experiências-reflexões, segundo Axt (2001), obtidas mediante contínuos deslizamentos entre estes mundos, distintos mas entrelaçados, ao coordenarem-se, poderão criar um " efeito de Real, permitindo à Educação, pelo exercício da interpretação, explorar novos possíveis modos de aprender-sentirconhecer-conceituar-comunicar, e assim inaugurar formas alternativas de entendimento do Real - Social”.

\section{FLEXIBILIDADE EM EDUCAÇÃO SUPERIOR: PRIMEIRAS CONCLUSÕES}

Bates (1995) aponta para a multiplicidade de operações, funções, situações em que o adulto universitário precisa dar conta na sua carreira acadêmica. Segundo ele, as 
teorias de aprendizagem para o Século XXI devem levar em consideração aprendizes capazes de manipular diferentes recursos e de maneiras diversas, com estilos próprios de aprendizagem e propósitos distintos. O aprendiz-usuário deverá ser capaz de:

"working alone, interacting with learning material, which may be available locally or remotely; working collaboratively [...] in relationship with fellow workers at different remote sites[...]; with a more experienced worker, [...] or other less experienced colleagues. [...] Learners will also need to be able to work from home, or from a work-site, or while in transit”.

Ramal (2000) destaca, por sua vez, a potencialidade de transgressão e de subversão que o uso das Tecnologias de Informação e Comunicação possibilita aos usuários de EaD. Para a autora, as relações unilaterais, os textos lineares, os programas estruturados e fechados estão desafiados por propostas abertas e flexíveis. A transgressão pode representar um ponto de fuga às determinações prévias estabelecidas na concepção da plataforma, do programa ou da atividade.

A comunicação e a aprendizagem, no contexto da EAD, exigem novas competências cognitivas emocionais sociais, culturais do universitário. Esta área constitui hoje, um novo campo de pesquisa em cognição.

LEVY (1998) quando menciona que na virtualidade, um emissor pode ser um receptor, um mediador, a ponta ou o meio de uma mensagem, e dele começar tudo novamente com outra ordem, aponta que nada, diante dessa ótica, pode vir a constituirse tomando como premissas o que se tem em termos presenciais. Além deste aspecto, salienta BRAGA (2001, p.27). que não é possível, nestes tempos, simplificar e considerar interações apenas como 'ações mútuas entre produtor e receptor'. Para o autor o "processo de comunicação mediática é diferido no tempo e no espaço e difuso em relação aos destinatários [...] envolve relações amplas entre um subsistema produtor/produto e um subsistema receptor/produto, permeada por outras mediações".

Neste sentido, a quantidade e a qualidade das aprendizagens que podem ser obtidas na interação com a mídia "dependem certamente dos produtos aí em circulação; dos estímulos inerentes às linguagens mediáticas ativadas; das dimensões da aprendizagem; mas também das condições de prontidão e envolvimento do usuário determinadas por sua formação e suas experiências de vida".

A flexibilização das condições de aprendizagem, com maior escolha do tempo e ritmos pelo aprendiz se, por um lado, o coloca numa zona de conforto, por outro, exige um maior grau de organização, de iniciativa e de responsabilidade.

O professor, apesar de convencido da inevitabilidade do processo de individualização e de flexibilização no Ensino Superior, diante de grandes e continuas mudanças no mundo do trabalho e nas tecnologias de comunicação e informação, se vê de frente com uma multiplicidade de situações imprevisíveis, com a necessidade de novas habilidades e competências e referências para sua prática. Caberia, portanto pensar no "grau de flexibilização" sustentável e na sua gradual implementação no Ensino Superior.

\section{REFERÊNCIAS BIBLIOGRÁFICAS}


ALBERO, B. L'Autoformation en Contexte Institutionnel: du paradigme de l' instruction au paradigme de l'autonomie. Paris: L'Harmattan, 2000.

AXT, M., SCHCH, E.M.M. Ambientes de Realidade Virtual e Educação: que Real é este? In: Interface: Comunicação, Saúde, educação, UNESP 5(9): 11-32,ag/2001

BATES, T. The Future of Learning. First Presented at the Minister's Forum on Adult Learning Edmonton, Alberta, Canadá (1995) Disponível em http://bates.cstudies.ubc.ca

BRAGA, J. L., CALAZANS, R. Comunicação e educação: questões delicadas na interface. Hacker Editores, 2001.

CELARO, M., CRUSE, R. Tecnologies and impact: report on English Distance Learning Course. In: International conference on advances in infraestructure for eletronic business, sciences and on the internet, 2001, L'Aquila.Proceedings. Itália: SSGRR, 2001.

CELARO, M., PALADINI, E. .P., RODRIGUES, R, ASSUMPÇÃO, S. Quality and flexibility in higher education. In: European Distance Education Network Conference Rhodes Proceedings. Grécia: EDEN, 2003.

COLLIS, B., MOONEN, J. Flexible Learning in a digital world. Londres: Kogan ,2001. DAMÁSIO, A . R. O Erro de Descartes: emoção, razão e o cérebro humano. São Paulo, Companhia Das Letras, 2001.

FIALHO, A . F. P . Ciências e Cognição. Florianópolis: Insular, 2001.

LÉVY, P. L' intelligence collective: pour une anthropologie du cyberspace.Paris: La Decouverte/poche, 1997.

MATURANA, H. Emoções e Linguagem na Educação e na Política. Belo Horizonte: Editora UFMG, 2001.

MATURANA, H. Ontologia da Realidade. Belo Horizonte: Editora UFMG, 2001.

PETERS, O. Distance Education in Transition: New Trends and Challenges, Volume 5 Oldenburg : Bibliotheks- und Informations system der Universität, 2002.

RAMAL, A. C. Educação na Cibercultura. Porto Alegre: Ed. Artmed, 2002. 